\title{
Optogenetic Inhibition of Ventral Pallidum Neurons Impairs Context-Driven Salt Seeking
}

\author{
Stephen E. Chang, ${ }^{1}$ Elizabeth B. Smedley, ${ }^{1}$ Katherine J. Stansfield, ${ }^{2}$ Jeffrey J. Stott, ${ }^{1}$ and Kyle S. Smith ${ }^{1}$ \\ ${ }^{1}$ Department of Psychological and Brain Sciences, Dartmouth College, Hanover, New Hampshire 03755, and ${ }^{2}$ Department of Psychology and Neuroscience, \\ University of Colorado Boulder, Boulder, Colorado 80309
}

Salt appetite, in which animals can immediately seek out salt when under a novel state of sodium deprivation, is a classic example of how homeostatic systems interface with learned associations to produce an on-the-fly updating of motivated behavior. Neural activity in the ventral pallidum (VP) has been shown to encode changes in the value of salt under such conditions, both the value of salt itself (Tindell et al., 2006) and the motivational value of its predictive cues (Tindell et al., 2009; Robinson and Berridge, 2013). However, it is not known whether the VP is necessary for salt appetite in terms of seeking out salt or consuming salt following sodium depletion. Here, we used a conditioned place-preference procedure to investigate the effects of optogenetically inhibiting the VP on context-driven salt seeking and the consumption of salt following deprivation. Male rats learned to associate one context with sucrose and another context with lessdesirable salt. Following sodium depletion, and in the absence of either sucrose or salt, we found that inhibiting the VP selectively reduced the elevation in time spent in the salt-paired context. VP inhibition had minimal effects on the consumption of salt once it was made available. To our knowledge, this is the first evidence that the VP or any brain region is necessary for the ability to use contextual cues to guide salt seeking. These results highlight a dissociation between deficit-driven reward seeking and reward consumption to replenish those deficits, with the former process being particularly sensitive to on-line VP activity.

Key words: salt appetite; ventral pallidum

\section{Significance Statement}

Salt appetite, in which rats will immediately seek out a once-undesirable concentrated salt solution after being depleted of bodily sodium despite never having tasted salt as a positive reward, is a phenomenon showing how animals can update their motivational goals without any new learning or conditioning. This salt-seeking behavior is also observed when the animal is presented with salt-paired cues. The neural circuitry necessary for context-driven salt-seeking behavior is unknown. We used a novel conditioned place preference procedure to show that optogenetic inhibition of the ventral pallidum (VP), a region known for processing reward, impairs context-driven salt seeking and has minimal effects on the consumption of salt itself following sodium depletion. These results highlight the importance of the VP in context-driven reward-seeking behavior.

\section{Introduction}

Survival requires an ability to modify behavior based on physiological needs. Changes in adaptive motivated behavior of this sort can occur through an integration of physiological signals with previously

\footnotetext{
Received Sept. 21, 2016; revised April 28, 2017; accepted May 2, 2017.

Author contributions: S.E.C. and K.S.S. designed research; S.E.C., E.B.S., K.J.S., and J.J.S. performed research; S.E.C., E.B.S., K.J.S., J.J.S., and K.S.S. analyzed data; S.E.C., E.B.S., K.J.S., and K.S.S. wrote the paper.

This work was supported by funding from National Institutes of Health Grant F32MH106178 (S.E.C.), National Institute on Drug Abuse Grant T32 NIDA037202 (J.J.S.), and from Whitehall Foundation Research Grant 2014-05-77 (K.S.S.). We thank Alyssa DiLeo, for assistance with histology, and Samuel Gardner, Vincent Chen, and Ryan Hyon, for assistance with behavioral training and data scoring.

The authors declare no competing financial interests.

Correspondence should be addressed to Stephen Chang, 6207 Moore Hall, Hanover, NH 03755. E-mail: Stephen.Chang@dartmouth.edu.

DOI:10.1523/JNEUROSCI.2968-16.2017

Copyright $\odot 2017$ the authors $\quad 0270-6474 / 17 / 375670-11 \$ 15.00 / 0$
}

learned information regarding food sources. A striking example is the salt-appetite phenomenon, in which animals immediately seek out a once-undesirable salt solution when encountering a novel state of sodium deprivation (Richter, 1936; for review, see Geerling and Loewy, 2008). Following sodium depletion, rats will show increases in lever-pressing behavior for salt (Wagman, 1963) or to a previously salt-paired lever alone (Krieckhaus and Wolf, 1968), and the rate of lever pressing increases with the degree of sodium deprivation (Quartermain et al., 1967).

Animals under sodium deprivation will demonstrate adaptive salt seeking without ever having experienced a concentrated salt solution as pleasant (Fudim, 1978; Robinson and Berridge, 2013). Thus, adaptive salt seeking is regarded as a special form of a nonincremental behavioral adaptation (Dayan and Berridge, 2014). For example, following sodium deprivation, rats will im- 
mediately engage with a cue that had previously been paired with oral infusion of a highly concentrated salt solution (Robinson and Berridge, 2013). Similarly, rats are able to use contextual cues under extinction conditions to flexibly shift their preferences to a salt-paired context, depending on their deprivation state (Stouffer and White, 2005).

In addition to hormonal modulation (Zhang et al., 1984; Sakai et al., 1986, 1987), several brain regions implicated in motivation and reward learning have been shown to be important for deprivationinduced salt drinking to replenish the deficit. These include the lateral hypothalamus (LH; Wolf and Quartermain, 1967; Tandon et al., 2012), the central nucleus of the amygdala (CeA; Galaverna et al., 1993; Seeley et al., 1993; Tandon et al., 2012; Hu et al., 2015), and the nucleus accumbens (NAc; Roitman et al., 2002; Voorhies and Bernstein, 2006; Loriaux et al., 2011; Tandon et al., 2012).

Much less is known about the neural circuitry mediating the ability of salt-paired cues to guide salt seeking. Correlative studies have implicated areas, including the NAc, the ventral pallidum (VP), and the ventral tegmental area in salt seeking, which exhibit heightened activity in response to salt-paired cues following sodium deprivation as though to represent the updated value of those cues (Tindell et al., 2009; Robinson and Berridge, 2013). However, tests demonstrating a causally necessary role of a brain area for appetite-induced salt seeking remain to be conducted. Thus, it is unknown whether mechanisms for salt seeking are the same as, or dissociable from, those for the primary motivation to consume salt. One likely candidate for regulating salt-seeking is the VP, a key region for motivated behavior (Cromwell and Berridge, 1993; Smith et al., 2009; Root et al., 2015; Ahrens et al., 2016). Of note, VP neurons do not normally respond to cues predicting an aversive salt outcome (Tindell et al., 2009). Yet, after sodium depletion, VP neural activity immediately becomes accentuated to the salt-predicting cue as a correlate of the adaptive change in cue-triggered motivation caused by salt appetite.

To evaluate whether VP activity is necessary for contextdriven salt-seeking behavior, we assessed the consequences of optogenetically suppressing VP activity as rats would normally seek out salt in a novel deprivation state. We designed a placepreference measure, rooted in prior work (Stouffer and White, 2005), in which animals associate separate contexts with sucrose and salt, and then, following salt depletion, immediately develop a preference for the salt-paired environment. Using this task, we found that VP disruption diminished salt seeking based on environmental cues and had minimal effects on salt consumption itself. These findings highlight a critical and specific role for the VP in integrating physiological states with learned environmental information to guide adaptive motivated behavior.

\section{Materials and Methods}

Animals. The subjects were male Long-Evans rats $(n=37$; Charles River), which weighed $250-300 \mathrm{~g}$ on arrival. Rats were pair-housed on arrival in a climate-controlled colony room illuminated from 7:00 A.M. to 7:00 P.M. Following surgery, rats were individually housed for the duration of the experiment and were given ad libitum access to food and water during recovery for 2 weeks. Rats were then placed on a foodrestriction schedule and maintained at $85 \%$ of their ad libitum weights for the duration of the experiment. The experiment was performed in accordance with the National Institute of Health's Guide for the Care and Use of Laboratory Animals, and protocols were approved by the Dartmouth College Animal Care and Use Committee.

Surgical procedures. Surgery was performed under aseptic conditions with isoflurane anesthesia. Viral vector injections were made with a 33 gauge beveled needle (World Precision Instruments) and a Quintessential Stereotaxic Injector (Stoelting). The coordinates for targeting the anterior/central VP were $0.12 \mathrm{~mm}$ anterior from bregma, $2.40 \mathrm{~mm}$ from the midline, and $8.20 \mathrm{~mm}$ ventral from the skull surface (variations in final expression shown in Fig. $1 I$ ). Infusions were made at $0.4 \mu \mathrm{l} /$ site at a rate of $0.15 \mu \mathrm{l} / \mathrm{min}$, and the syringe was left in place for $3 \mathrm{~min}$ to allow for diffusion. Rats in Group Halo $(n=17)$ received bilateral infusions of a halorhodopsin construct [AAV5-hSyn-eNpHR3.0-EYFP; Vector Core at the University of North Carolina (UNC Vector Core)], and rats in Group YFP/Control $(n=14)$ received bilateral infusions of a YFP-only construct (AAV5-hSyn-EYFP; UNC Vector Core). Optical fiber implants (10 $\mathrm{mm}$ in length, $200 \mu \mathrm{m}$ in diameter; Thorlabs or custom-made) were then lowered to $0.3 \mathrm{~mm}$ above the infusion sites. Bone screws and dental cement were affixed to the skull to anchor the fiber implants. We waited 3 weeks before the start of behavioral training.

Apparatus. Behavioral procedures, shown in Figure $1 A$, were performed using a custom-designed place-preference chamber $(29.5 \times$ $12.5 \times 21$ in; Dartmouth Apparatus Shop). The outside walls of the chamber were made of transparent acrylic. Plastic walls could be inserted to divide the chamber into three separate contexts during training. One context was designated the Grid context $(12.5 \times 12.5 \times 18.5$ in $)$, which consisted of a grid-patterned acrylic floor, walls with pieces of electrical tape on the outside arranged in a grid-like pattern, and bedding beneath the floor similar to the bedding in animal home cages. Another context of equivalent size was designated the Clear context, which had a clear acrylic floor, clear acrylic walls, and no bedding. Both contexts also contained two distinctive objects (a metal binder clip or an empty plastic coverslip case) to make it easier for animals to discriminate between contexts. Both contexts had holes on either end to accommodate spouts attached to bottles filled with each solution, thus making the solution available to rats inside the chamber. Connecting the Grid and Clear contexts was a Neutral context $(5 \times 12.5 \times 18.5$ in $)$ with clear acrylic walls. The Neutral context was the starting point for every training day and test session throughout the experiment.

Behavioral training. Rats underwent $8 \mathrm{~d}$ of training in which they learned to associate one context (Grid or Clear) with access to 3\% sucrose and the other context with access to $3 \%$ salt. Each solution also contained $2 \mathrm{~g}$ of sugar-free Kool-Aid powder (orange or grape) to aid discrimination. The assignment of context, solution, and Kool-Aid flavor pairings was all made pseudorandomly across rats but kept constant within rats. For each training day, rats were placed into the Neutral context and allowed access to only one context for $20 \mathrm{~min}$ (access to the other context was blocked). Rats could freely drink from $100 \mathrm{ml}$ of either sucrose or salt. Rats were trained in each context for $4 \mathrm{~d}$. The order of context exposure during training was counterbalanced across rats.

After the first $8 \mathrm{~d}$ of training, a baseline preference test session was given in which the rats were placed in the Neutral context and allowed free access to both the Grid and Clear contexts for the first time for 20 min. The conditions of the contexts were identical to training except the flavored solutions did not contain sucrose or salt. In addition, optogenetic cables (200 $\mu \mathrm{m}$ diameter; Thorlabs or Doric Lenses) were attached to the implants to familiarize rats to the cables, but no laser stimulation was given. Following the baseline test session, rats underwent 4 more days of retraining ( $2 \mathrm{~d}$ in each context). After the last day of retraining, rats were given systemic injections of the diuretic furosemide $(10 \mathrm{mg} / \mathrm{ml} /$ $\mathrm{kg}$, i.p.; Merck) to deplete rats of bodily sodium. To maintain sodium deprivation, rats were given a sodium-free food diet (TestDiet) and distilled water for the remainder of the experiment. After $48 \mathrm{~h}$, the now sodium-depleted rats were then placed back into the chamber with access to both contexts for a second preference test session identical to the baseline test session (i.e., no sucrose or salt present). Rats in both groups received yellow $(593.5 \mathrm{~nm})$ light delivery through bilateral fiber implants using a diode-pumped solid-state laser, patch cords, beam splitter, and rotary joint. Illuminations were given on a $3 \mathrm{~s}$ on, $3 \mathrm{~s}$ off train throughout the duration of this test session. This cycle was used to avoid heating and provide comparable light on/off time for the session. Based on measuring the amount of power from the end of a dummy fiber implant, the estimated light power in the brain was $4.2-4.3 \mathrm{~mW}$. Using an available light transmission calculator (http://web.stanford.edu/group/dlab/cgi-bin/ graph/chart.php) and known irradiance values to evoke eNpHR3.0 photocurrents at 50\% maximum and at close to $0 \%$ (Mattis et al., 2011), we 
A 1

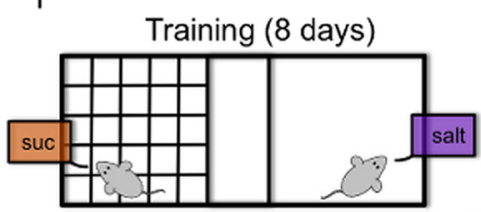

2

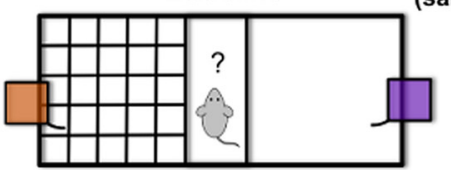

followed by 4 days of retraining
3

Depletion

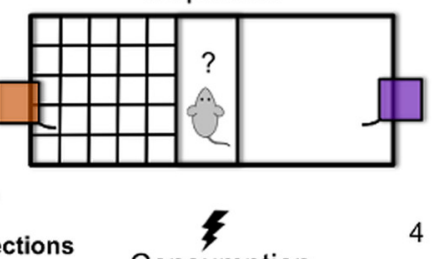

4
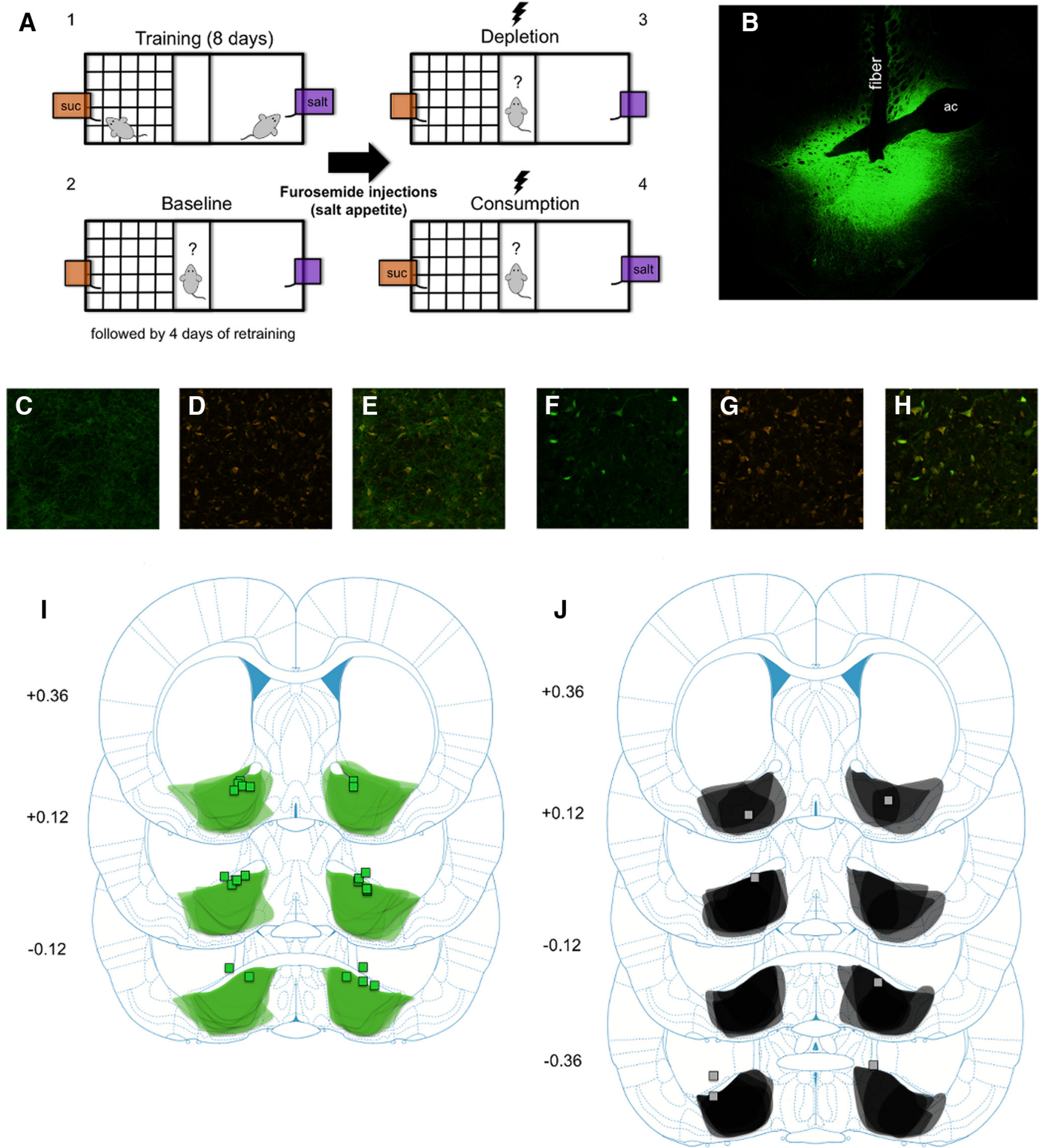

Figure 1. A, Behavioral procedure: rats were trained to associate one context with access to sucrose and another context with access to salt (4 $\mathrm{d}$ in each context, 20 min per session). Rats were then given a baseline test in which they were allowed access to both contexts for the first time in the absence of sucrose or salt (flavored solutions still present). After $4 \mathrm{~d}$ of retraining ( $2 \mathrm{~d}$ in each context), rats were sodium-depleted with furosemide ( $10 \mathrm{mg} / \mathrm{kg}$, i.p.). After $48 \mathrm{~h}$, rats were given a depletion test identical to the baseline test except that now rats received yellow laser stimulation ( 3 s on, 3 s off train). Finally, rats were given a consumption test identical to the depletion test but now sucrose and salt were available in each solution. $\boldsymbol{B}$, Representative brain slice from a Halo rat showing eNpHR3.0-EYFP expression in the VPand fiber track. ac, Anterior commissure. $\boldsymbol{C}-\boldsymbol{E}$, Example of eNpHR3.0-EYFP, Neurotrace, and coexpression of each from a brain slice of a rat that received AAV5-hSyn-eNpHR3.0-EYFP infusions in the VP.F-H, Example of EYFP, Neurotrace, and coexpression of each from a brain slice of a rat that received AAV5-hSyn-EYFP infusions in the VP. I, Schematic diagram of eNpHR3.0-EYFP expression in the VP (shading overlay) and fiber implant placements (squares) from all Halo rats ( $n=12$ ). Numbers on the left are number of millimeters from bregma. Illustrations adapted from Paxinos and Watson (2009).J, Schematic diagram of eNpHR3.0-EYFP expression in the VP (shading overlay) and fiber implant placements (squares) from all rats classified as Misses $(n=5)$. Note that three placements are not mapped due to either the fiber placement being too anterior and not above or within the VP (beyond $0.36 \mathrm{~mm}$ from bregma; $n=2$ ) or the fiber placement was unable to be located $(n=1)$. Numbers on the left are number of millimeters from bregma. Illustrations adapted from Paxinos and Watson (2009). 
estimate that $\sim 0.4 \mathrm{~mm}$ below our fiber tip neurons were $50 \%$ maximally inhibited, and at $\sim 1 \mathrm{~mm}$ below the fiber neurons were not robustly responsive. On the next day, rats were then given a final preference test session with access to both contexts again with laser stimulation, except now sucrose and salt were available in their respective contexts. Following this test session, rats were placed back on their normal food and water diet.

Experimental design and statistical analyses. The primary measures we analyzed were the amount of solutions consumed during training and test sessions (in milliliters), the number of entries into each context during test sessions, the amount of time spent in each context during test sessions, and the duration of time spent consuming solutions during test sessions. In addition, the amount of time spent in each context and time spent consuming solutions was also analyzed in 5 min blocks. For analyses that included multiple data points from each subject, repeatedmeasures ANOVAs were used. For analyses that included only a single data point from each subject based on a priori test plans, generalized linear models were used.

Repeated-measures ANOVAs were used to analyze separately the amount of each solution consumed during acquisition with the between-subjects factor of Group (Halo, YFP/Control) and a within-subjects factor of Session (Days 1-4, Days 5-6 analyzed separately). For test sessions, elevation scores were calculated for each measure by computing the difference between the depletion and baseline tests. In addition, we calculated the proportion of time spent in the salt-paired context relative to both contexts for the baseline and depletion tests. We also analyzed the time spent in the salt-paired context when the laser was on compared with when the laser was off for Halo rats. For each of these measures, generalized linear models were used to analyze any group differences. For analysis of the $5 \mathrm{~min}$ time blocks, repeated-measures ANOVAs were used to analyze the raw data from the depletion test for each group separately with within-subjects factors of Context (Sucrose, Salt) and Block (1-4). In addition, repeated-measures ANOVAs were used to analyze the amount of time spent consuming solutions (in $5 \mathrm{~min}$ blocks) during the consumption test for each group separately with within-subjects factors of Solution (Sucrose, Salt) and Block (1-4). Any significant interactions were followed up with generalized linear models using Bonferroni's correction for multiple comparisons. Otherwise, all analyses had a rejection criterion of $p<0.05$.

Histological procedures. Following behavioral testing, rats were anesthetized with sodium pentobarbital $(100 \mathrm{mg} / \mathrm{kg})$ and perfused intracardially with $0.9 \%$ saline, followed by $10 \%$ formalin. Brains were extracted, placed in 20\% sucrose, and then sliced in $40 \mu \mathrm{m}$ sections. After being mounted on microscope slides, sections were coverslipped using a DAPIcontaining hard-set mounting medium (Vectashield, Vector Laboratories). EYFP expression was verified using a fluorescent microscope (Olympus). Areas of EYFP expression and fiber implant placements were mapped onto corresponding figures of the Paxinos and Watson (2009) atlas. To confirm that eNpHR3.0 and EYFP were expressed in neurons, an additional stain with Neurotrace (Thermo Fisher Scientific) was conducted on an additional set of rats ( $n=8$; 4 Halo, 4 YFP/Control). Colocalization of eNpHR3.0/EYFP and Neurotrace expression was verified using a confocal fluorescent microscope (Nikon).

Recordings. VP units were recorded from two male Long-Evans rats, which were housed as above and maintained on ad libitum food during recordings. At least 3 weeks after halorhodopsin virus infusion, as above, rats were implanted with a head-stage consisting of 8-12 drivable tetrodes (four $12.5 \mu \mathrm{m}$ nichrome wires at $150-200 \mathrm{k} \Omega$ impedance). The head-stage was anchored to the skull using cranial screws and cement. Two head-stages were used, one an eight-tetrode drive with a fiber in the center of a tetrode bundle for unilateral recording and the other a 12-tetrode drive with two fibers bundled each with six tetrodes for bilateral recording. In both cases, the fiber was glued to the tetrodes, which protruded $0.5-1 \mathrm{~mm}$ beyond the fiber tip. Each fiber-tetrode bundle was drivable.

Tetrodes were lowered to the VP over the ensuing week. Recordings were made in a conditioning chamber $(31 \times 33 \times 34.5 \mathrm{~cm}$; Med Associates $)$ as rats were allowed to move freely. Multiple recording sessions were conducted using a 96-channel digital Neuralynx system and Cheetah acquisition software. Electrical signals were amplified at $100-1000 \times$, sampled at $32 \mathrm{kHz}$, filtered for $600-6000 \mathrm{~Hz}$, and recorded to a computer. An A.M.P.I. Master-9 signal generator triggered light pulses through the laser at a $3 \mathrm{~s}$ on, 3 s off cycle for $20 \mathrm{~min}$. Light deliveries were timestamped with electrical recordings. The potential of repeatedly sampling the same units across sessions was reduced by lowering tetrodes in $\sim 40 \mu \mathrm{m}$ increments before each session to acquire new units. Recorded waveforms were sorted into separate units using Plexon Offline Sorter. Units were analyzed for differences in mean firing rates in light-on versus light-off periods using NeuroExplorer and SPSS software and $t$ tests. Per-unit activity was calculated by dividing each time bin by average baseline activity to assess average response magnitudes and durations. Normalized activity was plotted by taking activity in light-on bins divided by the average activity in the light-off period. Additional $t$ tests were used to compare activity to the light-off average activity in sequential $0.2 \mathrm{~s}$ bins. Following the completion of recordings, current $(25 \mu \mathrm{A}, 10 \mathrm{~s})$ was passed through each tetrode to create small lesions for later localization. Brains were then removed, sectioned, and analyzed as above.

To assess potential photoelectric artifacts, a separate eight-tetrode head-stage was constructed identically to the implanted one above. Tetrodes were placed in saline (Han et al., 2009; Kravitz et al., 2013) and a $77.5 \mathrm{mV}, 1 \mathrm{kHz}$ sine wave was passed through for recording (panel ground reference, light $0.5-1 \mathrm{~mm}$ from fiber tip at the $3 \mathrm{~s}$ on/off cycle, 20 min recording duration). This setup would isolate photoelectric artifacts completely from any neuronal activity, allowing us to detect any voltage deflections purely associated with light on/off periods and to assess the similarity in those deflections with actual neuronal spike recordings.

\section{Results}

\section{Histology}

Figure $1 B$ is a representative brain slice from a Halo rat showing eNpHR3.0-EYFP expression in the VP along with the track from the fiber implant. Although eNpHR3.0-EYFP expression extended beyond the borders of the VP in both the anterior-posterior and mediolateral planes, all implant placements were located either within the VP or just above it. Figure $1 C-H$ shows images of EYFP, Neurotrace (a neuron-selective fluorescent label), and colocalization of both in the same cells of Halo and YFP/Control rats. Cells positive for EYFP but not Neurotrace were not observed. Figure $1 I$ is a map of eNpHR3.0-EYFP expression and fiber implant placements from all Halo rats that had acceptable expression and implant placements in the anterior/central VP $(n=12)$. Halo rats that did not have bilateral fiber placements within or just above the VP were categorized as Misses $(n=5$; Fig. $1 J)$. All YFP/Control rats had acceptable EYFP expression and fiber placements $(n=14)$. Rats classified as Misses did not differ from YFP/Control rats in any measure ( $p>0.05$ for all) except for the amount of salt consumed following sodium depletion once it was made available. Based on elevation scores calculated from the last day that rats consumed salt during training, rats in the Misses group drank more salt than YFP/Control rats following sodium depletion (Misses: $5.8 \mathrm{ml}$; YFP/Control: $2.9 \mathrm{ml} ; p=$ $0.025)$. Because this was the only difference between Misses and YFP/Control rats and the deficits due to VP inhibition were observed in prior tests, Misses were combined with YFP/Control rats into one YFP/Control group $(n=19)$. On the day of the baseline test session, one of the bottles of solutions was spilled after running a Halo rat. Therefore, we removed that rat's consumption data from that specific analysis $(n=11)$, but included that rat's data for every other measure for the other analyses $(n=12)$.

\section{Recordings}

We recorded $19 \mathrm{VP}$ cells that were responsive to light delivery: 12 cells were inhibited and 7 cells were excited. Figure $2 \mathrm{~A}$ shows the average normalized activity of inhibited cells during the $3 \mathrm{~s}$ period before light delivery (Pre-Light), during light delivery (Light), and during the $3 \mathrm{~s}$ period after light delivery (Post-Light). Note the data for the Pre-Light and Post-Light periods are identical due to the continuous light on/off delivery cycle ( $3 \mathrm{~s}$ on/off). Inhib- 


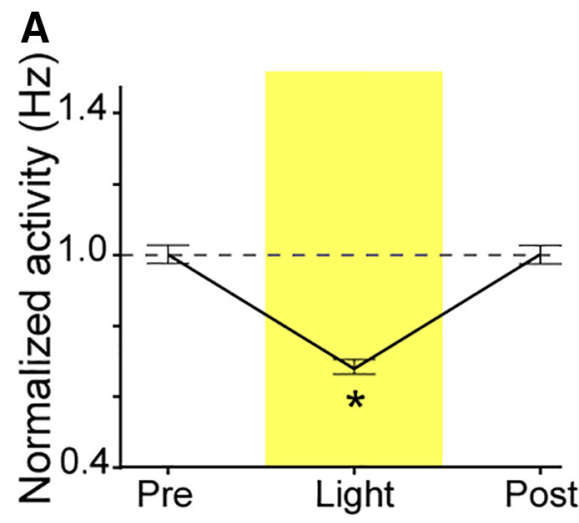

B

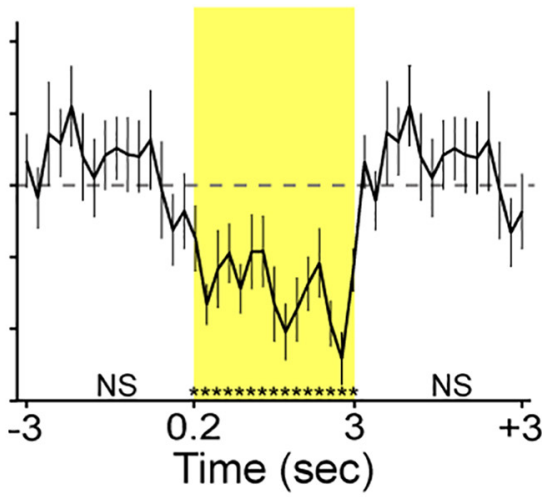

C

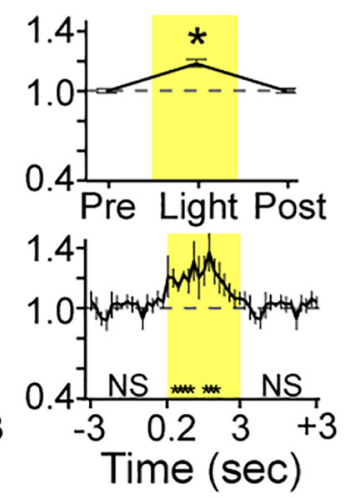

D

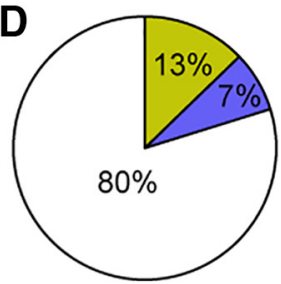

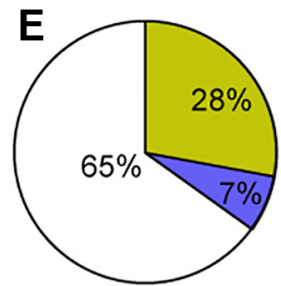
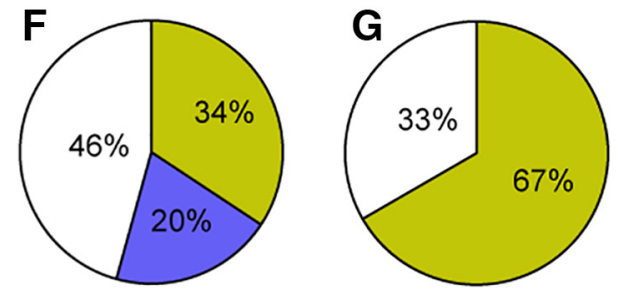

$\square$ No change
$\square$ Inhibited
$\square$ Excited

Figure 2. $\quad \boldsymbol{A}$, Normalized activity of inhibited cells $(n=12)$ during the $3 \mathrm{~s}$ period before light delivery (Pre-Light), during light delivery (Light), and during the $3 \mathrm{~s}$ period after light delivery (Post-Light). Note the data for the Pre-Light and Post-Light periods are identical due to the continuous light on/off delivery cycle (3 s on/off). B, Activity of inhibited cells during the Pre-Light, Light, and Post-Light periods in $200 \mathrm{~ms}$ bins. C, Top, Normalized activity of excited cells $(n=7)$ during the Pre-Light, Light, and Post-Light delivery periods. Bottom, Activity of excited cells during the Pre-Light, Light, and Post-Light periods in $200 \mathrm{~ms}$ bins. D, Proportion of inhibited units out of total recorded units. $\boldsymbol{E}$, Proportion of inhibited units out of total recorded units on tetrodes that ever had an inhibited unit on any recording session. $\boldsymbol{F}$, Proportion of inhibited units out of total recorded units from tetrodes that had an inhibited or excited unit on that same recording session. $\mathbf{G}$, Proportion of inhibited units out of total recorded units from the tetrodes on which the inhibited unit was recorded during each session. Error bars represent the SEM. ${ }^{*} p<0.05$ compared with baseline average. ns, Not significant.

ited cells produced a $31 \%$ reduction in firing on average. Figure $2 B$ shows the activity of inhibited cells during these same periods in $0.2 \mathrm{~s}$ bins. $T$ tests comparing each $200 \mathrm{~ms}$ bin of the lightdelivery period showed that all $0.2 \mathrm{~s}$ bins were significantly reduced compared with baseline (before or after light delivery). There were no significant changes in activity in any $0.2 \mathrm{~s}$ bin before or after light delivery, suggesting a precisely time-locked firing-inhibition effect of light. The prelight dip in activity (Fig. $2 B$ ) is not significant compared with baseline. On inspection of the units, it appeared to result from units with bursty activity having troughs spuriously aligned at this time. For example, one unit had normalized baseline activity that ranged from 0.1 to 2.1 $\mathrm{Hz}$ during baseline, and from 0.2 to $1.1 \mathrm{~Hz}$ during illumination, thus being dampened overall in activity by the light but retaining activity variability.

Figure $2 C$, top, shows the normalized activity of excited cells during the Pre-Light, Light, and Post-Light delivery periods. Of excited cells, there was a much weaker $19 \%$ overall increase in activity on average. Figure $2 C$, bottom, shows the activity of excited cells during these same periods in $0.2 \mathrm{~s}$ bins. $T$ tests confirmed that, in contrast to inhibited cells, excited cells showed significant increases in activity that started slower, in the $0.2-0.4 \mathrm{~s}$ bin after light onset, and that occurred in total for only $1 \mathrm{~s}$ during the $3 \mathrm{~s}$ light-delivery period. A subset of neurons exhibiting excitation at a slower latency is commonly observed in such preparations, and is likely due to those cells lacking the opsin yet being modulated by larger circuit dynamics (Anikeeva et al., 2011; Smith et al., 2012).

We additionally analyzed the proportion of recorded units inhibited or excited by light (Fig. $2 D-G$ ). We note that it is unclear whether the recorded units that were not responsive were within the range of effective illumination given that impedance was relatively low and some tetrodes were $1 \mathrm{~mm}$ from the fiber. To deal with this uncertainty, we calculated a range of possible proportions of responsive units including the following: (1) proportion of inhibited units out of total recorded units (13\%), (2) proportion of inhibited units out of total recorded units from tetrodes that had an inhibited or excited unit in that same recording session (34\%; isolating only tetrodes that recorded responsive units), (3) proportion of inhibited units out of total recorded units from the tetrodes on which the inhibited unit was recorded during each session (67\%; isolating only tetrodes that recorded an inhibited unit), and (4) proportion of inhibited units out of total recorded units on tetrodes that ever had an inhibited unit in any recording session (28\%; isolating only tetrodes that at some time recorded an inhibited unit). These numbers indicate that the proportion of inhibited neurons in the VP ranged from 13 to $67 \%$.

No evidence of photoelectric artifacts was observed in the high-frequency-filtered spike data. Single-unit activity always had amplitudes on the different tetrode wires unlike what would be expected from artifacts, did not have large voltage deflections at the time of light onset or offset as can occur (Kozai and Vazquez, 2015), and lacked complex waveforms that could have emerged from simultaneous photoelectric artifact and spiking. Most importantly, we note that photoelectric artifacts by their nature are observed in such recording preparations as phasic excitations, which would not have been factors in the inhibitions we report. Photoelectric artifacts were also not observed in our spike recordings where tetrodes were immersed in saline, similar to related reports where such artifacts appear in lower-frequency filtered signals (Han et al., 2009; Kravitz et al., 2013). There were no voltage deflections that differentiated light on/off periods, no spike-like waveforms present in the saline recordings, no complex waveforms that could implicate photoelectric artifacts com- 


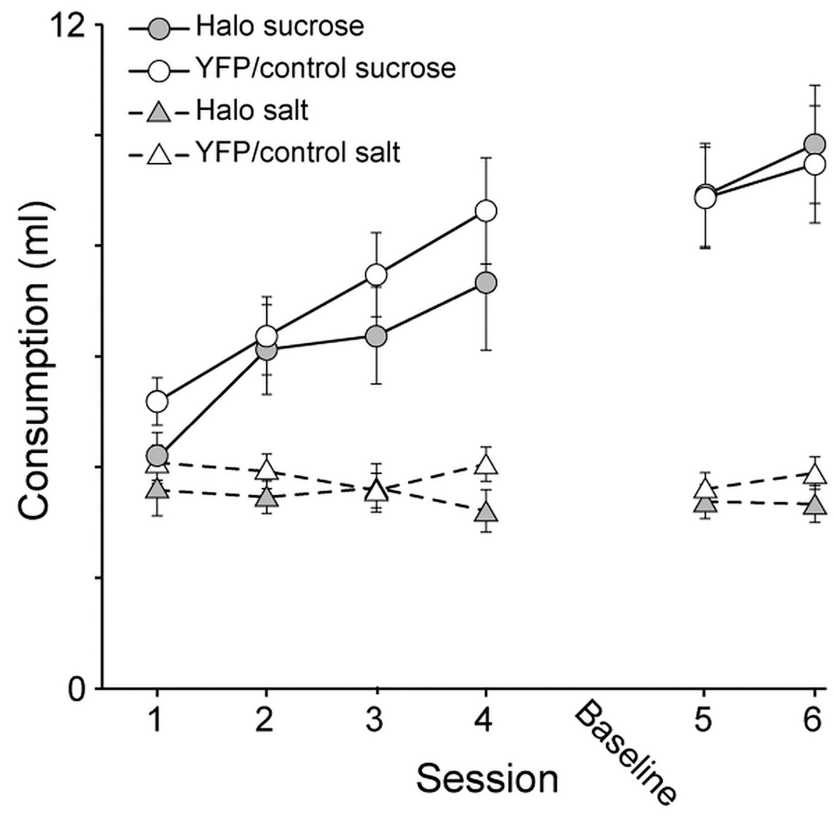

Figure 3. Amount of sucrose and salt solutions consumed over the first $4 \mathrm{~d}(1-4)$ and the last $2 d(5,6)$ of training following the baseline test session (Baseline). There were no group differences between Halo and YFP/Control rats. Error bars represent \pm SEM.

bined with the sine wave, and no clustering of waveforms outside of the sine wave and ambient noise.

\section{Acquisition}

Figure 3 presents the amount of solution consumed across the $6 \mathrm{~d}$ of training in each context. As expected, both groups consumed more sucrose than salt during training. Sucrose consumption increased across days, while salt consumption remained low. There were no differences between groups. In terms of sucrose consumption, a repeated-measures ANOVA over the first $4 \mathrm{~d}$ confirmed an effect of Session $\left(F_{(3,87)}=14.7, p<0.01\right)$ but no effect of Group $\left(F_{(1,29)}=0.86, p=0.36\right)$ or Group $\times$ Session interaction $\left(F_{(3,87)}=0.41, p=0.75\right)$. For the $2 \mathrm{~d}$ of training after the baseline test session, a repeated-measures ANOVA confirmed a marginal effect of Session $\left(F_{(1,29)}=4.04, p=0.054\right)$ and no effect of Group $\left(F_{(1,29)}=0.02, p=0.89\right)$ or Group $\times$ Session interaction $\left(F_{(1,29)}=0.17, p=0.68\right)$. In terms of salt consumption, a repeated-measures ANOVA confirmed no effects over the first $4 \mathrm{~d}(p \geq 0.26)$ and for the $2 \mathrm{~d}$ of training after the baseline test $\operatorname{session}(p \geq 0.27)$.

\section{Test}

Time in context

Depletion test. Figure $4 A$ presents the elevation in time spent in the sucrose-paired and salt-paired contexts during the depletion test compared with the baseline test. Importantly, there was no sucrose or salt present during these test sessions. In direct comparison, YFP/Control rats spent $131.6 \%$ more time in the saltpaired context compared with Halo rats following sodium depletion $(p=0.038)$. There were no group differences in the amount of time spent in the sucrose-paired context following sodium depletion $(p=0.16)$. In addition, there were no group differences in the amount of time spent in the Neutral context following sodium depletion, with Halo and YFP/Control rats showing a similar average decrease in time spent in the Neutral context compared with baseline $(p=0.24)$. Figure $4 B$ plots the proportion of time spent in the salt-paired context compared with the total amount time spent in both the sucrose-paired and salt-paired contexts during the baseline and depletion tests. Further confirming the deficit observed with elevation scores, YFP/ Control rats spent a greater amount of time in the salt-paired context during the depletion test than in the baseline test $(p<$ $0.01)$, while Halo rats showed no difference $(p=0.42)$. When the amount of time spent in the salt-paired context during the depletion test was analyzed for Halo rats in relation to when the laser was on or off, there were no differences. On average, Halo rats spent $245.4 \mathrm{~s}$ in the salt-paired context when the laser was off compared with a nearly identical $244.1 \mathrm{~s}$ when the laser was on (data not shown; $p=0.97$ ).

Figure $4 C, D$ plots the amount of time spent in the sucrose-paired and salt-paired contexts during the depletion test in 5 min blocks for Halo rats and YFP/Control rats, respectively. Across all 5 min blocks, Halo rats did not spend more time in the salt-paired context compared with the sucrose-paired context. In contrast, YFP/Control rats spent more time in the salt-paired context than in the sucrose-paired context across all 5 min blocks. For YFP/Control rats, a repeatedmeasures ANOVA confirmed an effect of Context $\left(F_{(1,18)}=13.99\right.$, $p<0.01)$ and Block $\left(F_{(3,54)}=4.03, p=0.01\right)$ but no Context $\times$ Block interaction $\left(F_{(3,54)}=0.68, p=0.57\right)$. For Halo rats, a repeatedmeasures ANOVA confirmed no effects $(p \geq 0.21)$. Thus, halorhodopsin-evoked inhibition of the VP blocked the appetiteinduced preference for the salt-paired context.

Consumption test. This effect of halorhodopsin during the depletion test appeared specific to context-driven salt seeking, as it did not affect behavior much when animals were allowed to consume the salt and sucrose in the subsequent consumption test (Fig. 4E,F). During this test, both Halo and YFP/Control rats generally spent more time in the salt-paired context than in the sucrose-paired context during the first half of the test session, the time when both groups drank the salt solution (below). This difference went away over the second half of the test session, as salt drinking similarly declined (below). An ANOVA on Halo rats confirmed no main effects of Context $\left(F_{(1,11)}=1.11, p=0.32\right)$ or 5 min Block $\left(F_{(3,33)}=1.32, p=0.28\right)$ but a significant Context $\times$ Block interaction $\left(F_{(3,33)}=3.96, p=0.02\right)$. Analysis of each time block with generalized linear models revealed that Halo rats spent significantly more time in the salt-paired context compared with the sucrose-paired context during only the second block ( $p<0.01$, Bonferroni corrected). In contrast, an ANOVA for YFP/Control rats confirmed that they spent more overall time in the salt-paired context than in the sucrose-paired context during the test session with a main effect of Context $\left(F_{(1,18)}=7.73, p=0.01\right)$. Additionally, there was an effect of Block $\left(F_{(3,54)}=5.48, p<0.01\right)$, but no Context $\times$ Block interaction $\left(F_{(3,54)}=2.47, p=0.07\right)$.

\section{Number of entries}

Figure 5 shows the elevation in the number of entries into the sucrose-paired and salt-paired contexts following sodium depletion compared with the baseline test session. Entries did not differ between groups. Both Halo and YFP/Control rats showed comparable decreases in the number of entries regardless of context $(p \geq 0.87)$. This decrease was likely due to habituation to the environment from the baseline exposure to the depletion test exposure, as presumably the ability to explore all three chambers was more novel the first time (baseline test).

\section{Drinking}

Paired flavors (depletion test). Figure $6 A$ shows the elevation in the amount of sucrose-paired and salt-paired flavored solutions consumed during the depletion test compared with the baseline test 
(sucrose and salt were not present during either test, only their paired flavors). There was a marginal effect of YFP/Control rats drinking less of the sucrosepaired solution than Halo rats $(p=0.052)$ and no group difference in drinking the salt-paired solution $(p=0.55)$. Although there was no significant difference between groups in terms of the amount of each flavored solution consumed, YFP/ Control rats consumed significantly more salt-paired flavor than sucrose-paired flavor. Halo rats also consumed more saltpaired flavor than sucrose-paired flavor, but the difference was not as great (Halo: $p=0.07$; YFP/Control: $p<0.01$, withingroup comparisons). In short, animals with VP inhibition did not quite significantly favor the salt-paired flavor over the sucrose-paired flavor, and yet while YFP/ Controls did, the groups were no different in overall salt-flavor consumption in direct comparison.

Salt and sucrose (consumption test). Figure $6 B$ shows the elevation in consumption of the sucrose-paired and salt-paired solutions following sodium depletion once sucrose and salt were made available. These elevation scores were computed by calculating the difference between the amount of sucrose and salt consumed on the last day of training from the amount rats consumed during the test session. The increase in salt consumption was comparable across groups ( $p=0.99$ group comparison), as was the decrease in sucrose consumption ( $p=0.94$ group comparison). Both groups consumed more salt than sucrose following sodium depletion (Halo: $p<0.01$; YFP/Control: $p<0.01$ within group comparisons), which confirms that rats were sodiumdepleted. Thus, evidence demonstrated that both groups exhibited a salt appetite in terms of consumption measures.

To explore this further, we assessed the time spent consuming sucrose and salt solutions in 5 min blocks (Fig. 6C,D). YFP/ Control rats spent more time drinking the salt solution compared with the sucrose solution over the first two blocks, but this difference was no longer observed over the second two blocks. Although Halo rats also showed a similar trend as YFP/Control rats, the difference observed in the first two blocks was statistically significant only for YFP/Control rats after correction for multiple comparisons. An ANOVA for Halo rats confirmed no effect of Solution $\left(F_{(1,11)}=1.09, p=\right.$ $0.32)$, but an effect of Block $\left(F_{(3,33)}=5.63, p<0.01\right)$ and a Solution $\times$ Block interaction $\left(F_{(3,33)}=4.37, p=0.01\right)$. Although this suggested differential drinking of salt across time, an analysis of each 5 min block using generalized linear models (Bonferroni corrected) revealed no significant differences (Block $1, p=0.15$; Block Bonferroni's correction.
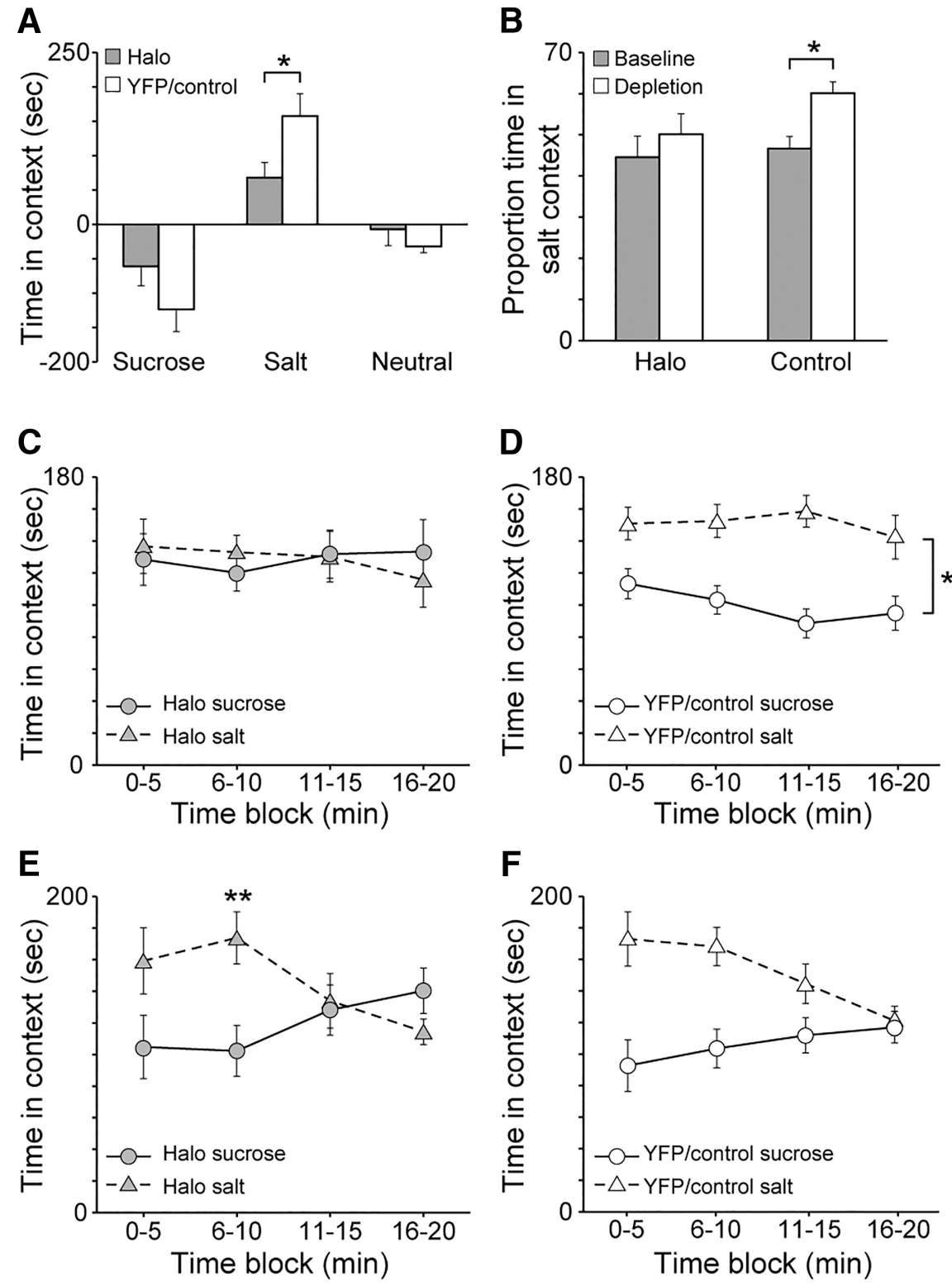

Figure 4. A, Elevation in time spent in sucrose-paired and salt-paired contexts during the depletion test following sodium depletion compared with the baseline test. Compared with Halo rats, YFP/Control rats showed a greater elevation in time spent in the salt-paired context. There was no difference in time spent in the sucrose-paired context. $\boldsymbol{B}$, The proportion of time spent in the salt-paired context relative to the time spent in both the sucrose-paired and salt-paired contexts during the baseline and depletion tests. YFP/Control rats spent a greater proportion of time in the salt-paired context following sodium depletion during the depletion test compared with the baseline test. Halo rats showed no differences. C, Amount of time Halo rats spent in the sucrose-paired and salt-paired contexts during the depletion test in 5 min blocks. Halo rats did not show any differences in time spent in one context versus the other context across the entire session. $\boldsymbol{D}$, Amount of time YFP/Control rats spent in the sucrose-paired and salt-paired contexts during the depletion test in 5 min blocks. Control rats spent more time in the salt-paired context compared with the sucrose-paired context across the entire session. $E$, Amount of time Halo rats spent in the sucrose-paired and salt-paired contexts during the consumption test in 5 min blocks. Halo rats spent significantly more time in the salt-paired context than in the sucrose-paired context during only the second block. $F$, Amount of time YFP/Control rats spent in the sucrose-paired and saltpaired contexts during the consumption test in $5 \mathrm{~min}$ blocks. YFP/Control rats spent significantly more time in the salt-paired context than in the sucrose-paired context during the first two blocks. Error bars represent the SEM. ${ }^{*} p<0.05 ;{ }^{* *} p<0.0125$ after

$2, p=0.11$ ), suggesting that the timing difference was more subtle. An ANOVA for YFP/Control rats similarly confirmed main effects of Solution $\left(F_{(1,18)}=4.66, p=0.045\right)$, Block $\left(F_{(3,54)}=25.86, p<\right.$ $0.01)$, and a Solution $\times$ Block interaction $\left(F_{(3,54)}=15.57, p<0.01\right)$. In contrast to Halo rats, analysis of each block using generalized linear models (Bonferroni corrected) revealed that YFP/Control rats 


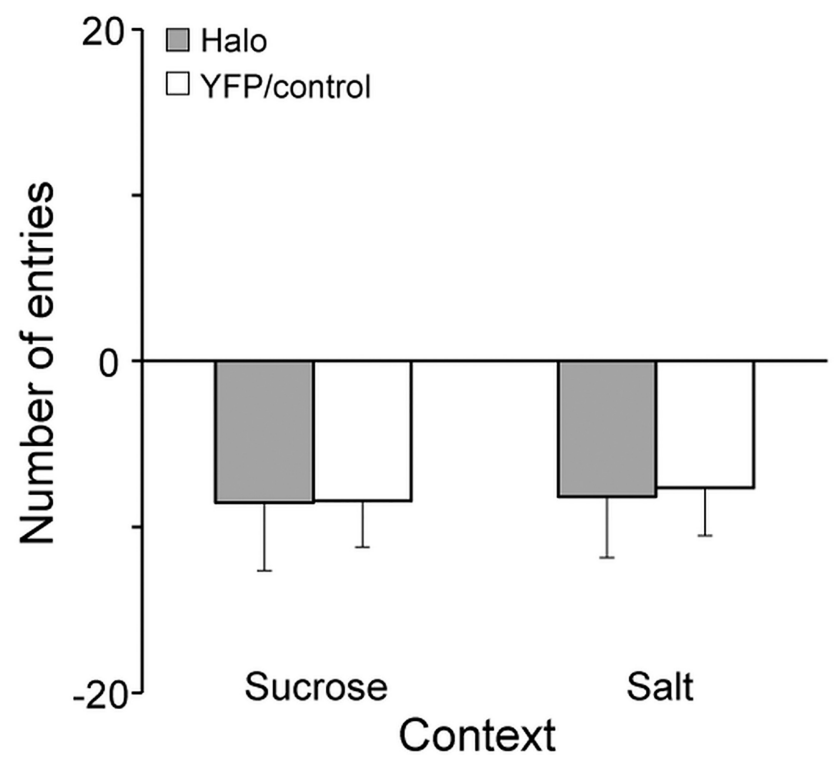

Figure 5. Elevation in the number of entries into the sucrose-paired and salt-paired contexts during the depletion test following sodium depletion compared with the baseline test. Halo and YFP/Control rats showed no differences. Error bars represent the SEM.

spent more time consuming the salt solution compared with the sucrose solution over the first two blocks ( $p$ 's $<0.01$ ). Together with the elevation in salt consumption following sodium depletion, these results suggest that VP inhibition did not reduce the motivation to pursue and consume salt following sodium depletion once salt was made available.

\section{Posterior VP perturbation}

Of the 17 rats initially designed to target the central VP, five rats that were not included in the above data analysis had fiber placements within or above the VP that were located $\geq 0.36 \mathrm{~mm}$ behind bregma (range, -0.36 to $-0.60 \mathrm{~mm}$ ). In contrast, rats included in the above data analysis (Group Halo; $n=12$ ) had fiber placements much more anterior (range, +0.36 to -0.12 $\mathrm{mm}$ ). Thus, we separately analyzed the data from rats fortuitously having more posterior fiber placements (Group Posterior Halo; $n=5$ ). Figure $7 A$ presents a map of eNpHR3.0-EYFP expression and fiber implant placements from all Posterior Halo rats. Other than showing a greater decrease in time spent in the Neutral context compared with baseline following sodium depletion $(p<0.01)$, Group Posterior Halo rats showed no differences compared with YFP/Control rats in terms of any measure (elevation in time spent in sucrose-paired and salt-paired contexts: $p \geq$ 0.51 ; Fig. $7 B$; proportion of time in salt-paired context: $p \geq 0.10$; elevation in number of entries: $p \geq 0.30$; elevation in consumption: $p \geq 0.18$ ). Similarly, when analyzed in terms of $5 \mathrm{~min}$ bins, these rats also showed a clear salt-seeking increase that was observed throughout the session (Context: $F_{(1,4)}=18.1, p=0.01$; Block: $F_{(3,12)}=1.2, p=0.34$; Context $\times$ Block: $F_{(3,12)}=0.17, p=$ 0.91 ; Fig. $7 C)$, and they consumed more salt than sucrose following sodium depletion $(p<0.01$; Fig. $7 D)$. Following sodium depletion, Group Posterior Halo rats compared directly with Halo rats showed a greater elevation in time spent in the saltpaired context (similar to YFP/Control rats; $p<0.01$ ).

\section{Discussion}

Salt appetite is an example of how the integration of physiological needs and prior experience with food sources can dramatically modify motivated behavior (Krieckhaus and Wolf, 1968; Fudim, 1978). The seeking of salt in this case can occur immediately, before new learning or conditioning, as a form of on-the-fly updating of motivational goals (Tindell et al., 2009; Dayan and Berridge, 2014). Here, using a place-preference procedure, we show that the VP is necessary for this updating, and is thus critical for integrating learned information with nutritional deficits to drive context-driven goal seeking. The lack of any robust effect of VP inhibition on consuming a salt-paired flavor, which had accrued attractive value after the depletion in similar fashion to the context, suggested that the salt pursuit based on context preferentially required VP involvement. This finding, along with the minimal change in salt consumption itself, highlights an important neural dissociation in the VP for the seeking of needed nutrients versus their ingestion.

Interestingly, this immediate change in salt seeking following sodium depletion is not always observed, specifically when rats are trained to press a lever or pull a chain for salt delivery (Dickinson, 1986). Despite other work suggesting that salt seeking is immediate when rats are trained to press a lever for salt delivery (Krieckhaus and Wolf, 1968), the contrasting results of Dickinson (1986) and those using Pavlovian procedures (Robinson and Berridge, 2013; current study) suggests that salt appetite may be processed differentially under Pavlovian and instrumental settings.

\section{VP and cue-reward learning}

Neurons in the VP have been previously shown to encode the updating of the motivational value of salt-paired cues (Tindell et al., 2009; Robinson and Berridge, 2013). Traditionally regarded as a structure for translating motivation into behavior (Mogenson et al., 1980), evidence such as this instead suggests that the VP participates critically in the motivational processes themselves (Smith et al., 2009). For example, in recent work, we have shown that chemogenetic disruption of VP neurons reduces the motivational attraction to reward-paired cues (sign-tracking behavior) without affecting the expression of that motivation once it has been acquired (Chang et al., 2015). The results here provide further evidence that the VP is important for motivational processes that direct animals to reward cues.

\section{Anterior versus posterior VP}

The VP is a functionally heterogeneous structure. Pharmacologic manipulations of the whole VP can produce changes in motivation, for example in eating behavior, while manipulations of the posterior quadrant of the VP affects hedonic processing as well (Johnson et al., 1993; Stratford et al., 1999; Smith and Berridge, 2005). The area of the VP targeted here was in its anterior/central location, an area previously shown to be needed for the motivation to eat, place preferences for reward, and sign tracking (Hiroi and White, 1993; McAlonan et al., 1993; Smith and Berridge, 2005; Dallimore et al., 2006; Chang et al., 2015). While recognizing the lower subject numbers from fortuitous manipulations of the posterior VP, the clear lack of any effect trend on salt seeking is notable given that VP neural activity in this posterior zone tracks the change in the hedonic and incentive value of salt across appetite states (Tindell et al., 2006, 2009). However, our finding is consistent with recent work showing a preferential role for anterior but not posterior VP in cue-induced cocaine seeking (Mahler et al., 2014).

\section{Light-delivery cycles}

For Halo rats, the on/off cycle timing did not map on to changes in context-driven salt seeking. Considering that the cycles of light delivery were relatively short, it is possible that momentary 
changes in salt-seeking motivation were not reflected in the typically longerduration changes in movement between task contexts. Conversely, it is also possible that navigation to reward contexts is not regulated at the neural level momentto-moment, suggesting that the lack of difference between light on/off phases here could be due to a temporally long process for the VP to integrate stimuli and appetites that we sufficiently disrupted.

\section{General motor activity and salt consumption}

VP inhibition in our study had no apparent effect on general motor activity. Halo and YFP/Control rats showed comparable numbers of context entries, and both groups showed a reduction in the number of entries that were comparable regardless of context during the depletion test. We believe this reduction was due to habituation to the test environment from the baseline test to the depletion test. VP inhibition also had no effect on the consumption of salt following sodium depletion once it was made available. Both Halo and YFP/Control rats showed comparable increases in salt consumption and decreases in sucrose consumption following sodium depletion, suggesting the primary motivation to consume salt was unaltered. This is somewhat surprising given the role of the VP in the motivation to eat (Stratford et al., 1999; Smith et al., 2009; Root et al., 2015). The VP has also not been studied in relation to salt consumption following depletion, which is known to depend on such brain areas as the CeA and LH (Wolf and Quartermain, 1967; Galaverna et al., 1993; Seeley et al., 1993); the lack of impact of VP inhibition on salt consumption here could indicate that these other areas instead guide homeostatically regulated consummatory behaviors or else can compensate for the loss of VP involvement. The same question remains for depletioninduced increases in salt palatability, which is related to (posterior) VP activity (Tindell et al., 2006), but which could conceivably have survived the VP perturbations applied here.

\section{Conclusion and remaining questions}

The precise nature of the deficit observed here for salt seeking requires further studies to resolve, though we argue that the most parsimonious explanation of our results is one of a deficit in integrating learned cues with appetite states for context-driven salt seeking. For example, it is certainly possible that the VP plays a role in Pavlovian reward seeking of any kind (Smith et al., 2009). Thus, whether the VP is involved in salt or sucrose consumption and context-driven seeking for either under homeostatic conditions are unanswered questions that require future investigation. However, in such cases, after the value of the reward (e.g., sugar in a cue-sugar associative situation) is acquired, it remains mostly stable. When there is a motivational state change that must be integrated with such
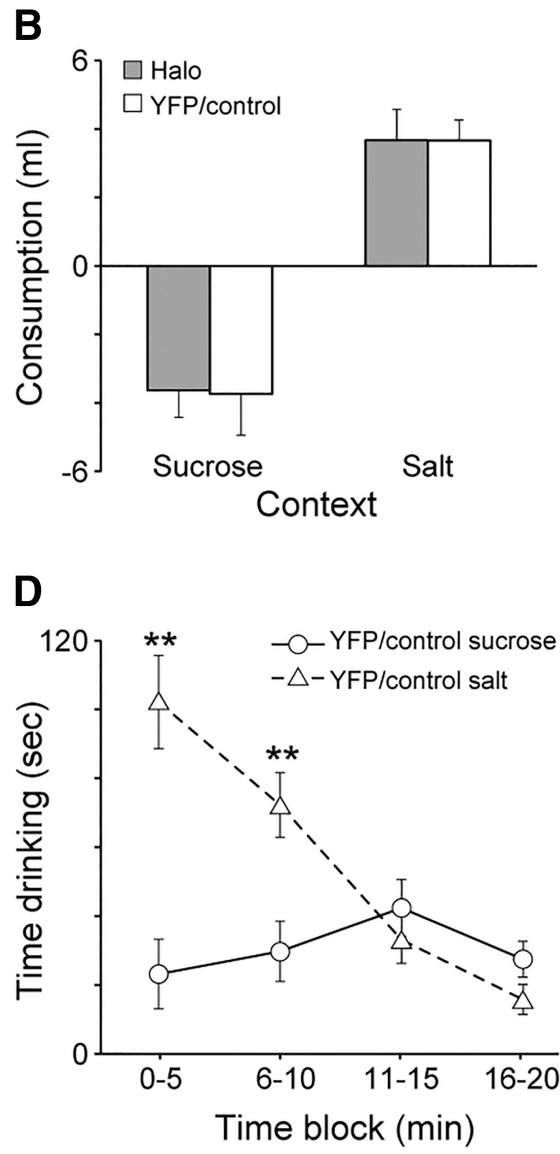

Figure 6. A, Elevation in the amount of solution consumed (without sucrose or salt) during the depletion test following sodium depletion compared with the baseline test. Although there were no differences between groups in terms of consumption of each flavor, YFP/Control rats consumed significantly more salt-paired flavor than sucrosepaired flavor. Halo rats also consumed more solution consumed (with sucrose and salt) during the consumption test following sodium depletion compared with the last day of . Halo and YFP/Control rats showed no differences. C, Amount of time Halo rats spent consuming sucrose-paired and shaw any statistical differences after correction for multiple comparisons. Amount of time YFP/Control rats spent consuming YFP/Control rats spent significantly more time drinking the salt-paired solution compared with the sucrose-paired solution during the first two blocks. Error bars represent the SEM. ${ }^{* *} p<0.0125$ after Bonferroni's correction.

associations to guide changes in reward seeking, there must be a brain mechanism to accomplish this. We argue that the VP is one such mechanism based on the results here, raising the question of whether other brain areas that represent predicted reward value in Pavlovian learning function similarly. We also note the similar reduction in time spent in the neutral context for Halo and YFP/Control rats during the depletion test compared with baseline, which suggests that the behavior of YFP/Controls after depletion reflected a motivational bias toward the salt context at the expense of the neutral and sucrose contexts rather than a bias away from sucrose. It then follows that the indiscriminate time that Halo rats spent between salt and sucrose contexts is best understood as a loss of their normal bias toward the salt context. This notion is also bolstered by the previous report that VP neurons acquire a response to cues predicting salt immediately after depletion, while their simultaneous response to sugar cues remains strong and unchanged as the value of the sugar remains stable (Tindell et al., 2009). Separately, we recognize the possibility that the VP disruptions impaired context memory recall, as VP is needed for memory-guided tasks for reward (Floresco et al., 1999; Zhang et al., 2005). However, here, context 
A
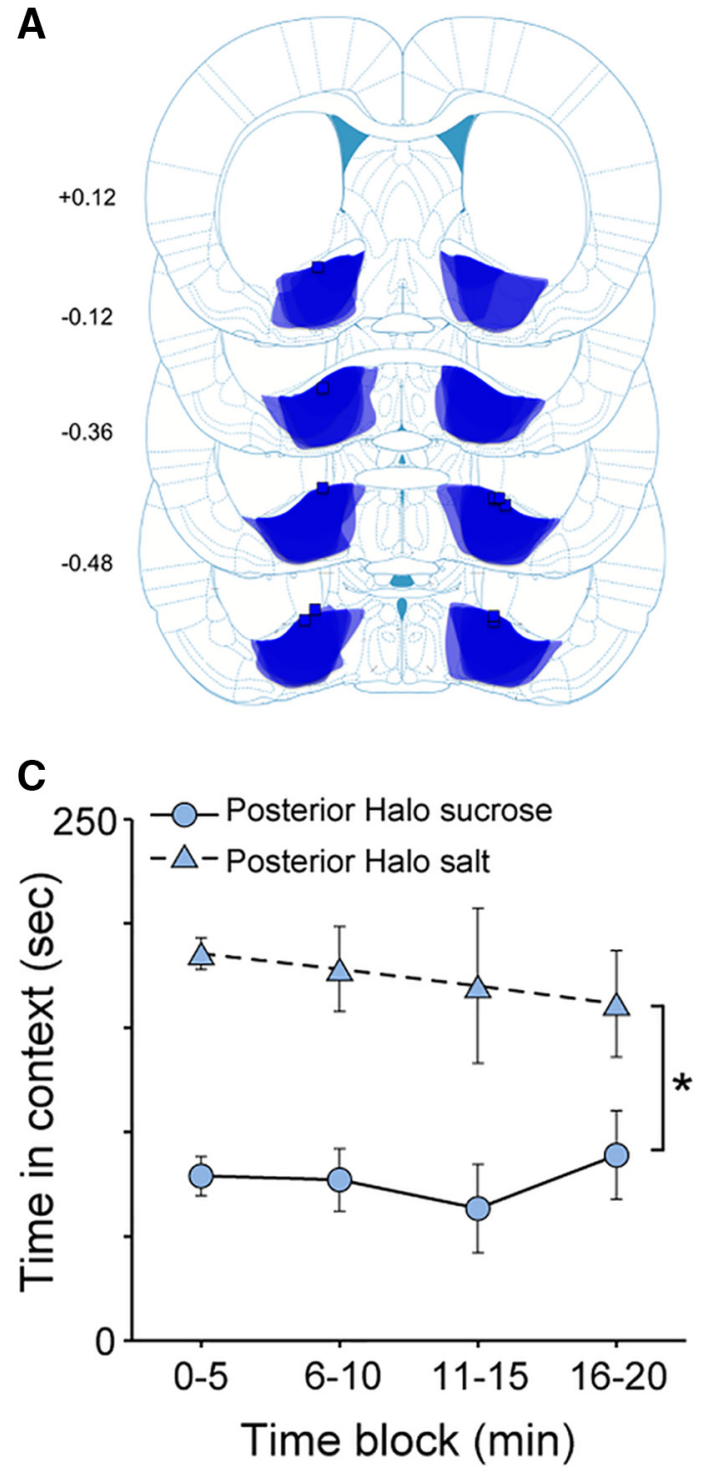

B
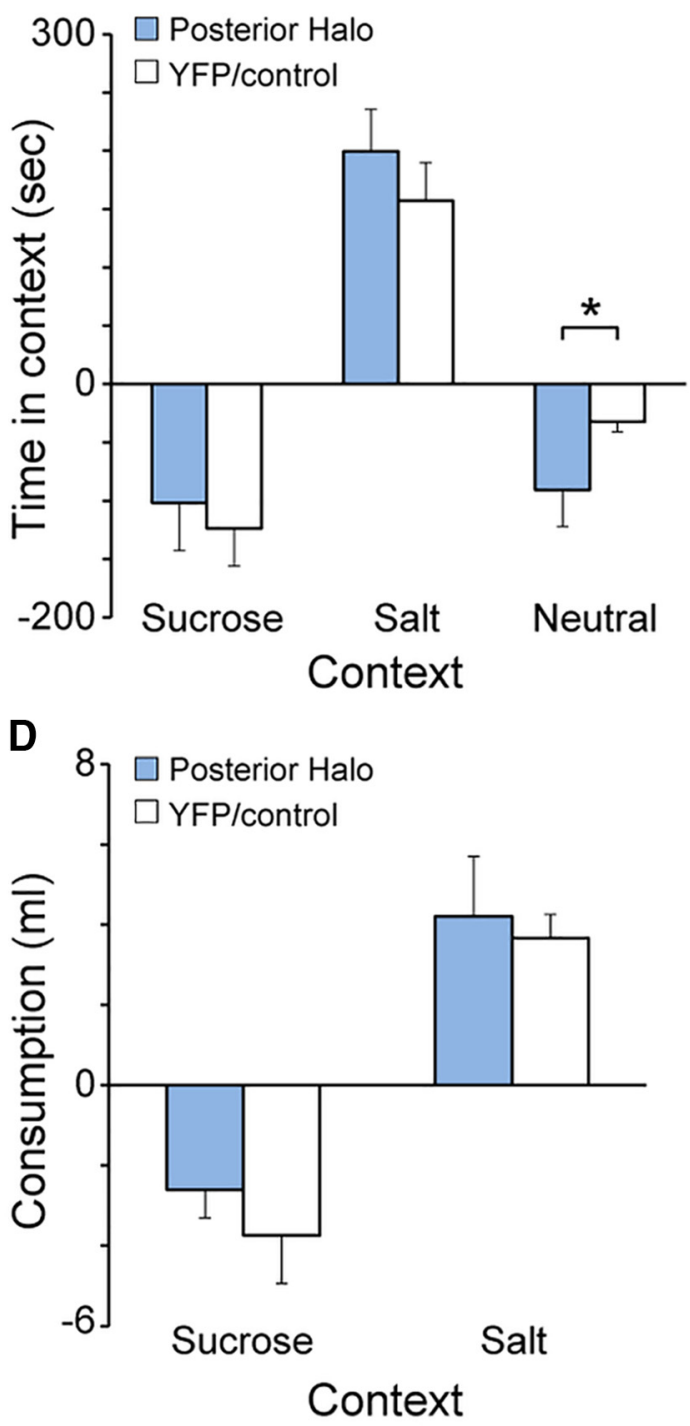

Figure 7. A, Schematic diagram of eNpHR3.0-EYFP expression in the VP (shading overlay) and fiber implant placements (squares) from all Posterior Halo rats $(n=5)$. Numbers on the left are number of millimeters from bregma. Illustrations adapted from Paxinos and Watson (2009). B, Elevation in time spent in sucrose-paired and salt-paired contexts during the depletion test following sodium depletion compared with the baseline test. C, Amount of time Posterior Halo rats spent in the sucrose-paired and salt-paired contexts during the depletion test in 5 min blocks. Posterior Halo rats spent more time in the salt-paired context than in the sucrose-paired context throughout the entire test session. $\boldsymbol{D}$, Elevation in the amount of solutions consumed (with sucrose or salt) during the consumption test following sodium depletion compared with the last day of training. Error bars represent the SEM.

entries might have been expected to rise in such a case if the animals were seeking salt but unable to recall contextual information. Given the above wealth of evidence for VP roles in stimulus-reward processing, we favor the interpretation that VP inhibition disrupted the linkage between homeostatic deficits, context-reward associations, and motivational output.

Although we observed a deficit in context-driven salt seeking after inhibiting VP activity, salt seeking was not completely abolished. Disinhibition of VP neurons not expressing eNpHR3.0, lack of complete VP inhibition, and other functionally complementary brain regions remaining online are all factors that may account for this. Indeed, we observed incomplete activity suppression (13-67\% of units inhibited; $31 \%$ inhibition level). This is consistent with other reports, most notably that of Anikeeva et al. (2011), who used a similar tetrode recording design and viral vector. They found $29 \%$ of recorded units exhibited firing inhibition, and in those a 53-83\% level of inhibition. Our prior work in the cortex similarly observed a 56\% inhibition in responsive neurons (Smith et al., 2012). The level of inhibition achieved here thus appeared typical, if slightly low. Of relevance as well, Kravitz et al. (2013) found 13\% of striatal cells responsive to light using a Cre-dependent channelrhodopsin-containing vector.

In summary, optogenetic inhibition of the VP impaired adaptive salt seeking following sodium depletion and had minimal effects on the consumption of salt once it was available. Uncovering a brain region that is causally, and preferentially, relevant for context-driven reward seeking based on appetite demands sets the stage for further investigation into brain-circuit mechanisms for this adaptive behavioral process.

\section{References}

Ahrens AM, Meyer PJ, Ferguson LM, Robinson TE, Aldridge JW (2016) Neural activity in the ventral pallidum encodes variation in the incentive value of a reward cue. J Neurosci 36:7957-7970. CrossRef Medline 
Anikeeva P, Andalman AS, Witten I, Warden M, Goshen I, Grosenick L, Gunaydin LA, Frank LM, Deisseroth K (2011) Optetrode: a multichannel readout for optogenetic control in freely moving mice. Nat Neurosci 15:163-170. CrossRef Medline

Chang SE, Todd TP, Bucci DJ, Smith KS (2015) Chemogenetic manipulation of ventral pallidal neurons impairs acquisition of sign-tracking in rats. Eur J Neurosci 42:3105-3116. CrossRef Medline

Cromwell HC, Berridge KC (1993) Where does damage lead to enhanced food aversion: the ventral pallidum/substantia innominata or lateral hypothalamus? Brain Res 624:1-10. CrossRef Medline

Dallimore JE, Mickiewicz AL, Napier TC (2006) Intra-ventral pallidal glutamate antagonists block expression of morphine-induced place preference. Behav Neurosci 120:1103-1114. CrossRef Medline

Dayan P, Berridge KC (2014) Model-based and model-free Pavlovian reward learning: revaluation, revision, and revelation. Cogn Affect Behav Neurosci 14:473-492. CrossRef Medline

Dickinson A (1986) Re-examination of the role of the instrumental contingency in the sodium-appetite irrelevant incentive effect. Q J Exp Psychol B 38:161-172. Medline

Floresco SB, Braaksma DN, Phillips AG (1999) Involvement of the ventral pallidum in working memory tasks with or without a delay. Ann NY Acad Sci 877:711-716. CrossRef Medline

Fudim OK (1978) Sensory preconditioning of flavors with a formalinproduced sodium need. J Exp Psychol Anim Behav Process 4:276-285. CrossRef Medline

Galaverna OG, Seeley RJ, Berridge KC, Grill HJ, Epstein AN, Schulkin J (1993) Lesions of the central nucleus of the amygdala. I: effects on taste reactivity, taste aversion learning and sodium appetite. Behav Brain Res 59:11-17. CrossRef Medline

Geerling JC, Loewy AD (2008) Central regulation of sodium appetite. Exp Physiol 93:177-209. CrossRef Medline

Han X, Qian X, Bernstein JG, Zhou HH, Franzesi GT, Stern P, Bronson RT, Graybiel AM, Desimone R, Boyden ES (2009) Millisecond-timescale optical control of neural dynamics in the nonhuman primate brain. Neuron 62:191-198. CrossRef Medline

Hiroi N, White NM (1993) The ventral pallidum area is involved in the acquisition but not expression of the amphetamine conditioned place preference. Neurosci Lett 156:9-12. CrossRef Medline

Hu B, Qiao H, Sun B, Jia R, Fan Y, Wang N, Lu B, Yan JQ (2015) AT1 receptor blockade in the central nucleus of the amygdala attenuates the effects of muscimol on sodium and water intake. Neuroscience 307:302310. CrossRef Medline

Johnson PI, Stellar JR, Paul AD (1993) Regional reward differences within the ventral pallidum are revealed by microinjections of a mu opiate receptor agonist. Neuropharmacology 32:1305-1314. CrossRef Medline

Kozai TD, Vazquez AL (2015) Photoelectric artefact from optogenetics and imaging on microelectrodes and bioelectronics: new challenges and opportunities. J Mater Chem B Mater Biol Med 3:4965-4978. CrossRef Medline

Kravitz AV, Owen SF, Kreitzer AC (2013) Optogenetic identification of striatal projection neuron subtypes during in vivo recordings. Brain Res 1511:21-32. CrossRef Medline

Krieckhaus EE, Wolf G (1968) Acquisition of sodium by rats: interaction of innate mechanisms and latent learning. J Comp Physiol Psychol 65:197201. CrossRef Medline

Liedtke WB, McKinley MJ, Walker LL, Zhang H, Pfenning AR, Drago J, Hochendoner SJ, Hilton DL, Lawrence AJ, Denton DA (2011) Relation of addiction genes to hypothalamic gene changes subserving genesis and gratification of a classic instinct, sodium appetite. Proc Natl Acad Sci U S A 108:12509-12514. CrossRef Medline

Loriaux AL, Roitman JD, Roitman MF (2011) Nucleus accumbens shell, but not core, tracks motivational value of salt. J Neurophysiol 106:1537-1544. CrossRef Medline

Mahler SV, Vazey EM, Beckley JT, Keistler CR, McGlinchey EM, Kaufling J, Wilson SP, Deisseroth K, Woodward JJ, Aston-Jones G (2014) Designer receptors show role for ventral pallidum input to ventral tegmental area in cocaine seeking. Nat Neurosci 17:577-585. CrossRef Medline

Mattis J, Tye KM, Ferenczi EA, Ramakrishnan C, O'Shea DJ, Prakash R, Gunaydin LA, Hyun M, Fenno LE, Gradinaru V, Yizhar O, Deisseroth K (2011) Principles for applying optogenetic tools derived from direct comparative analysis of microbial opsins. Nat Methods 9:159-172. CrossRef Medline
McAlonan GM, Robbins TW, Everitt BJ (1993) Effects of medial dorsal thalamic and ventral pallidal lesions on the acquisition of a conditioned place preference: further evidence for the involvement of the ventral striatopallidal system in reward-related processes. Neuroscience 52:605-620. CrossRef Medline

Mogenson GJ, Wu M, Jones DL (1980) Locomotor activity elicited by injections of picrotoxin into the ventral tegmental area is attenuated by injections of GABA into the globus pallidus. Brain Res 191:569-571. CrossRef Medline

Paxinos G, Watson C (2009) The rat brain in stereotaxic coordinates. New York: Academic.

Quartermain D, Miller NE, Wolf G (1967) Role of experience in relationship between sodium deficiency and rate of bar pressing for salt. J Comp Physiol Psychol 63:417-420. CrossRef Medline

Richter CP (1936) Increased salt appetite in adrenalectomized rats. Am J Physiol 115:155-161.

Robinson MJ, Berridge KC (2013) Instant transformation of learned repulsion into motivational "wanting". Curr Biol 23:282-289. CrossRef Medline

Roitman MF, Na E, Anderson G, Jones TA, Bernstein IL (2002) Induction of a salt appetite alters dendritic morphology in nucleus accumbens and sensitizes rats to amphetamine. J Neurosci 22:RC225. Medline

Root DH, Melendez RI, Zaborszky L, Napier TC (2015) The ventral pallidum: subregion-specific functional anatomy and roles in motivated behaviors. Prog Neurobiol 130:29-70. CrossRef Medline

Sakai RR, Nicolaïdis S, Epstein AN (1986) Salt appetite is suppressed by interference with angiotensin II and aldosterone. Am J Physiol 251:R762R768. Medline

Sakai RR, Fine WB, Epstein AN, Frankmann SP (1987) Salt appetite is enhanced by one prior episode of sodium depletion in the rat. Behav Neurosci 101:724-731. CrossRef Medline

Seeley RJ, Galaverna O, Schulkin J, Epstein AN, Grill HJ (1993) Lesions of the central nucleus of the amygdala. II: effects on intraoral $\mathrm{NaCl}$ intake. Behav Brain Res 59:19-25. CrossRef Medline

Smith KS, Berridge KC (2005) The ventral pallidum and hedonic reward: neurochemical maps of sucrose "liking" and food intake. J Neurosci 25 8637-8649. CrossRef Medline

Smith KS, Tindell AJ, Aldridge JW, Berridge KC (2009) Ventral pallidum roles in reward and motivation. Behav Brain Res 196:155-167. CrossRef Medline

Smith KS, Virkud A, Deisseroth K, Graybiel AM (2012) Reversible online control of habitual behavior by optogenetic perturbation of medial prefrontal cortex. Proc Natl Acad Sci U S A 109:18932-18937. CrossRef Medline

Stouffer EM, White NM (2005) A latent cue preference based on sodium depletion in rats. Learn Mem 12:549-552. CrossRef Medline

Stratford TR, Kelley AE, Simansky KJ (1999) Blockade of GABAA receptors in the medial ventral pallidum elicits feeding in satiated rats. Brain Res 825:199-203. CrossRef Medline

Tandon S, Simon SA, Nicolelis MA (2012) Appetitive changes during salt deprivation are paralleled by widespread neuronal adaptations in nucleus accumbens, lateral hypothalamus, and central amygdala. J Neurophysiol 108:1089-1105. CrossRef Medline

Tindell AJ, Smith KS, Peciña S, Berridge KC, Aldridge JW (2006) Ventral pallidum firing codes hedonic reward: when a bad taste turns good. J Neurophysiol 96:2399-2409. CrossRef Medline

Tindell AJ, Smith KS, Berridge KC, Aldridge JW (2009) Dynamic computation of incentive salience: "wanting" what was never "liked". J Neurosci 29:12220-12228. CrossRef Medline

Voorhies AC, Bernstein IL (2006) Induction and expression of salt appetite: effects on Fos expression in nucleus accumbens. Behav Brain Res 172:90 96. CrossRef Medline

Wagman W (1963) Sodium chloride deprivation: development of sodium chloride as a reinforcement. Science 140:1403-1404. CrossRef Medline

Wolf G, Quartermain D (1967) Sodium chloride intake of adrenalectomized rats with lateral hypothalamic lesions. Am J Physiol 212:113-118. Medline

Zhang DM, Stellar E, Epstein AN (1984) Together intracranial angiotensin and systemic mineralocorticoid produce avidity for salt in the rat. Physiol Behav 32:677-681. CrossRef Medline

Zhang Y, Bailey KR, Toupin MM, Mair RG (2005) Involvement of ventral pallidum in prefrontal cortex-dependent aspects of spatial working memory. Behav Neurosci 119:399-409. CrossRef Medline 